\title{
A Design-Based Study for Development of a Model for a Successful Online Discussion Forum
}

\author{
Enjy Abouzeid, Faculty of Medicine, Suez Canal University, Egypt* \\ Anshoo Agarwal, Northern Border University, Saudi Arabia \\ Janneke M. Frambach, Maastricht University, The Netherlands
}

\begin{abstract}
Due to the current situation of lockdown and social distancing, many educational institutions have shifted to online learning. This study aims to identify the key factors that should be present for successful online discussion and explores the advantages of merging two activities, e-mentoring, and online discussion to improve the quality of the online discussion. A mixed methods design-based study was conducted in the setting of the online program in health professions education. Several success factors were identified by the current study: merging of mentorship and online discussion, shifting of roles, structuring of the discussion, assessment, and the use of guides. The study also magnified the role of supervision as moderation and mentorship and suggested solutions to deal with silent participants. Finally, the use of a student guide and shifting of roles between the students play a crucial role in the success of the ODFs.
\end{abstract}

\section{KEYWORDS}

E-Mentorship, FOMSCU, Health Professions Education, JMHPE, Listserv, Maastricht University and Student Guide, Online Learning

\section{INTRODUCTION}

The COVID-19 pandemic has revealed the curtains of many important tools that can be used for online learning. Online discussion forum (ODF) is one of these tools. An online discussion forum is a web-based application that brings people together alongside shared interests and mindsets. The use of ODF has been identified as an important activity for engaging students besides the educational units or assignments (Balaji \& Charkrabarti, 2010). Due to the current situation of lock-down and social distancing, many educational institutions have shifted to online learning. This raises the need for a deeper understanding of the available tools that may foster the students' engagement and learning. Therefore, it is important to identify the success factors for the implementation of online discussion forums, especially due to a scarcity of literature on this topic.

Online discussion allows types of interactions that are difficult to achieve with other learning activities. Previous research confirmed the importance of online discussion for the quality of students' learning experience and showed that online discussions provide a medium for learning which promotes increased student engagement, satisfaction, critical analysis and reflection, and the social construction of knowledge (Chang, et al, 2015, Zhao, 2016 \& Delaney, D, 2019).). However, two main challenges 
face online discussions: 1) insufficient or inappropriate contribution of the participants (Hew, et al, 2010), and 2) lack of critical analysis and reflection in discussions (Garrison \& Cleveland-Innes, 2005).

Although several previous studies have investigated the factors and importance of online discussion in online programs, (Gerosa, et al, 2010, Ulrich \& Nedelcu, 2015, Liu, et al,2016, Lima, et al, 2019), most of these studies include a list of advantages, challenges, and strategies. However, there is a need for further research to address the uncertainty about the factors that may lead to the success or failure of this vital activity, as to our knowledge no study has primarily focused on identifying success factors, strategies, and suggested a possible design for implementation.

Moreover, the potential role of e-mentoring in the context of online discussion forums deserves further attention yet is underexplored in the literature. Virtual mentoring becomes a popular tool nowadays because it can provide a flexible and convenient method of communication between mentor and mentee in comparison to what traditional mentoring offers (Ramani, et al,2020). The main advantage of e-mentoring is the flexibility in time and space. E-mentoring can offer an economical and environmentally friendly way of mentoring according to the participants' time; it may reduce the mentors' and mentees' feeling of discomfort and it can provide quick supportive information or help (Rowland, 2012). Thus, merging e-mentoring with online discussions may improve the quality and performance of students in online discussions.

Accordingly, the current study contributes to this research stream to identify the key factors from the instructors' point of view that should be present for a successful online discussion and construct a new design to improve the quality of the online discussion. By investigating an intervention in a specific educational setting, three research questions are addressed:

1. How to design a successful online discussion?

2. What are the success factors to design and implement online discussion forums?

3. What is the effect of implementing e-mentorship on online discussion forums?

\section{BACKGROUND}

Communication is an important part of the excellence of online learning (Bakharia A, Dawson S., 2011, Koutropoulos A, et al,2012). Forums enable facilitators to realize and intercede in teaching and learning activities (Jiang Z, et al,2015, Stephens-Martinez K, et al,2014), and students have time to contemplate and frame answers. Learners jointly build up understanding while collaborating in an online milieu (Gilbert, PK., \& Dabbagh N., 2005). A well-organized educational forum is an important instrument to endorse contemplation on learning, impart information and perspectives, and unite learners (Benbunan-Fich R., Hiltz. SR., 1999). Forums can encounter both periods of sluggishness and sporadic flurries of posts (Filippo D, Fuks, H., de Lucena, CJP., 2009). Without proper input, a low level of cognitive commitment happens, and learners may feel cut off (Abawajy, J., \& Kim, T.,2011) that can lead to inadequate contribution or absence of deepness and excellence of the discussion (Watson, A.,2008).

Many studies done based on the review of literature focused on precise improvements to online discussion forums, looking into the list of advantages, difficulties, and strategies along with their main outcome (Watson, A.,2008, Liu M, et al,2016, Ulrich, C., \& Nedelcu. A.,2016, Sayfouri. N.,2016, Xu, B., Yang, D.,2015 \& Höver, K., \& Mühlhäuser, M.,2015). No study has predominantly focused on identifying advantages, threats, opportunities, and promising improvements from the facilitator's points of view. Understanding the perception and attitude of facilitators is imperative since they work intimately with a diversity of learners. In the studies done by Funaro and Montel (Funaro, G., \& Montell, F.,1999), Nandi et al. (Nandi, D, et al,2012.) and Balaji (Balaji, MS., \& Chakrabarti, D., 2012), online forums allowed learners and facilitators to share their wellbeing and find out the ways for good team workup. Discussions can lead to the building of novel knowledge among the learners (Katz, S., 2005). In addition, Brower (Brower, H.,2003) reports that online tools support 
quality discussions and joint learning, reaffirming the advantage of the deepness of working as team members. A study done by Garrison et al. (Garrison, Dr.,1999) reflected that, in online forums, the time between postings led to more thoughtful responses than those of face-to-face learning. Other major advantages include flexibility, expediency, and convenience for learners to complete their learning anytime and at any place (Balaji, MS., \& Chakrabarti, D., 2012). Their studies highlighted that online discussion forums avoid loss of data, as the students' written messages can be retrieved and reviewed anytime, reaffirming the benefit of information records for facilitators. They also stated that the use of online discussion forums permits learners to work together more with other students and facilitators (Balaji, MS., \& Chakrabarti, D., 2012). The online discussion forums provide important benefits for learners to dynamically connect in their learning process through participation. The learner -facilitators communication is a necessary part of the academic process (Anderson, T.,2006). Forums expand learners' opportunities for exchanging knowledge. According to Afify (Afify, MK.,2019), online forums provide students with the time needed to deal with their learning, share ideas, and share points of view on course topics. Other benefits for the online forum are the expansion of skills in virtual teams (Pendry. L., \& Salvatore J., 2009).

There are many difficulties regarding online discussion forums. The discussion forums do not facilitate the monitoring of active engagement of learners. According to Nakahara et al. (Nakahara, J.,2005), monitoring messages and learner's participation are time-consuming tasks. According to Machado et al. (MacHado, C.,2019), due to the considerable number of posts that are generated regularly, manual analysis becomes impossible. Mazzolini and Madison (Mazzolini, M.,2007) showed that the time of posts and the nature of their posts affect student participation. Rohfeld and Hiemstra (Rohfeld, R.,1995) describe the facilitators responsible for keeping discussions on track, contributing insights, providing discussion topics, and maintaining group harmony (Dennen, VP.,2005). Liu et al. (Liu, M.,2016) emphasize that many online forums can have a "poor" boundary. Coetzee et al. (Coetzee, D.,2014) has also studied how effectively organized online forum design affects student learning outcomes. According to Wise et al. (Wise, AF.,2015), facilitators and learners need to learn to focus on the messages that are relevant to their learning activities as due to a large number of participants discussion forums are often overwhelmed by information overload (Brinton, C.,2014). Often online forums become confusing for learners to follow the information in a sequential way (Hollands, F., \& Tirthali, D., 2014). Poquet and Dawson (Poquet, O.,2019) report that the high number of students and the nature of online courses make it difficult to develop a sense of belonging and confidence in educational forums.

This study was conducted in the setting of the online joint Master of Health Professions Education between Maastricht and Suez Canal Universities. The program was founded in 2002 as one of the first online programs in health professions education in the Arab region. It is a two-year program in which students follow several educational units and students participate in an online discussion forum through the web-based application Listserv.

\section{Study Design}

The study is design-based research that used mixed methods to obtain different but complementary data on the same topic to best understand the research problem. The study is divided into three stages as follows:

\section{a. Analyze and explore}

The listserv is a term that is frequently used in the program, it is an alternative name for online discussion in the literature. The listserv activity (online discussion forum) is a virtual e-group between fellows, in which the fellows are requested to actively participate in a discussion with other peers (current and previous fellows). The discussions are tailored around different themes. Those themes are purely Medical Education topics, and each discussion took 2 weeks duration. This activity is 
regulated by Listserv coordinators. The fellows are requested to participate in one or more (at least one) discussion throughout the whole program duration. The activity timing is scheduled with the start of the academic year. In addition, the coordinator announces the topic 2 weeks before the start of the discussion. Fellows were voluntarily asked to moderate one session, and this was scored by a bonus mark. However, all fellows didn't have the chance to be moderators through their study in the program.

To explore the online discussion situation during the use of the old version, an evaluation of the quality of the online discussion was done. The evaluation was done by using a scoring rubric that was included in a framework proposed by Nandi et. al. (2009). This framework defines several themes on which qualitative online interaction can be designed and assessed. The scoring rubric comprised three broad categories: content, interaction quality, and participation. The framework also provides a sub-classification that indicates what may be a poor, satisfactory, good, or excellent performance against each criterion (Nandi et.al, 2012). The evaluation was done by three independent raters. The scores were collected in one spreadsheet and the average score of each item was calculated. The evaluation results revealed that there were several problems in the depth and quality of contributions. Accordingly, modifications of the online discussion were needed.

\section{b. Design \& Construct}

As a first step to design and construct a new version of the ODFs, a focus group was conducted at the Faculty of Medicine with 10 experts from the Medical Education department and programs stakeholders. The sample was a purposive sample focused on including those who had knowledge and experience in the online discussion, was familiar with the online discussion, and worked as moderators. The sample group was homogenous concerning their working place. However, they were heterogeneous concerning their working experience that ranged from one year to more than 10 years, gender, the working role, and programs.

The participants received an email explaining the purpose and procedure of the study. Participants voluntarily accepted to participate in the study and signed an informed consent that was sent by email. Researchers had prepared a discussion guide including the questions and sequences. The questions were divided into personal questions about the role and experience in ODFs, questions about the success factors and tactics, and questions about the use of mentorship in ODFs.

The focus group lasted for two hours. The researcher adopted the directive style to better understand intriguing and specific items and factors that were identified by observation and literature review. Answers were recorded in audio and written forms. The focus group was transcribed and analyzed using principles of grounded theory (GT). It followed an inductive approach. Themes and categories were interpretative, constructed by the researchers from the data.

The focus group script/guide was organized into three categories: personal information, the success factors of online discussions, and the effect of mentorship on the online discussion. The script was transcribed and analysed using the procedures of the Ground theory (GT) method. Two coding steps were used: open (a procedure for developing categories of information), and axial (an advanced procedure for interconnecting the categories).

After the analysis of the focus group results. The researchers merge the factors and tactics suggested in the focus group and the existing learning theories to construct the new online discussion design. The design relies on the Cognitive Social Learning Theory. It adopted several concepts that aim to overcome the challenges that were identified during the exploration phase and improve the quality of the online discussions. Firstly, clear understanding of the nature and purpose of the activity from all the parties (Xie et al., 2006; Zhao \& McDougall, 2005). Secondly, total involvement of the students in the activity (sense of community); in terms of planning, implementation, assessment, and evaluation. (Delaney, et al, 2019) Thirdly, direct, and continuous contact and support from the 


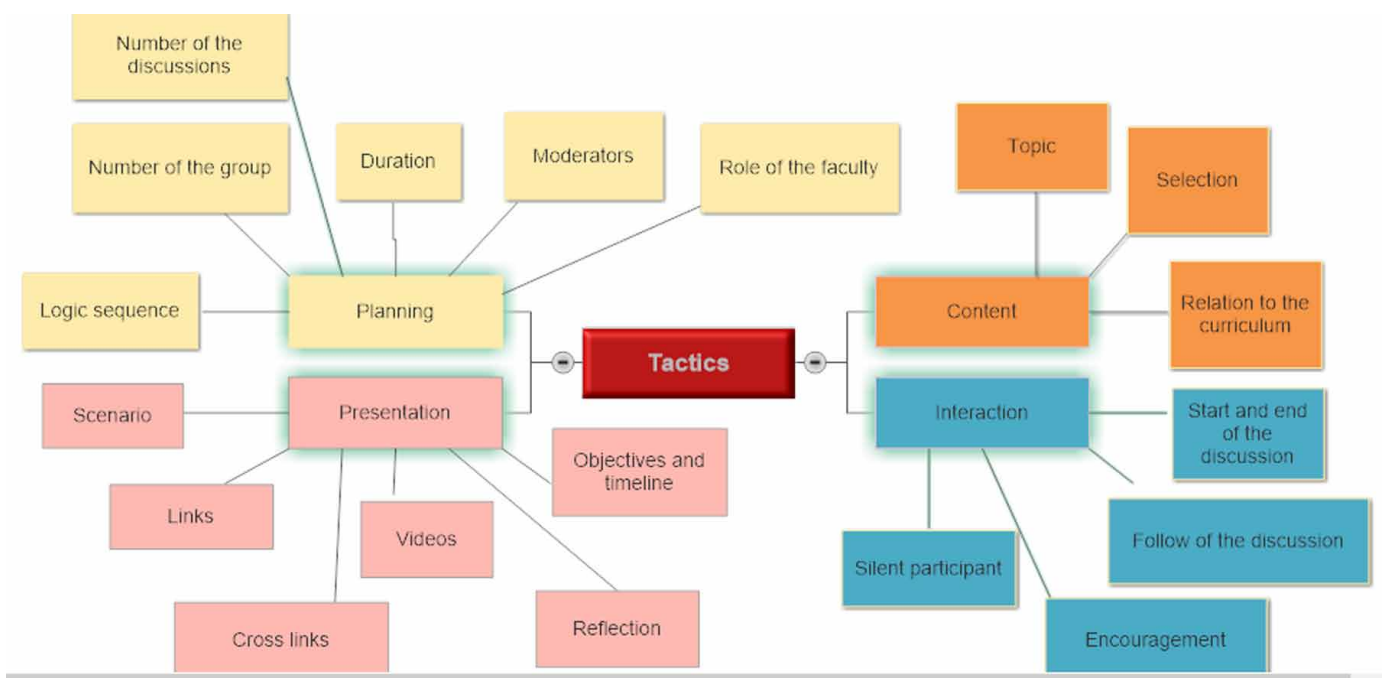

instructors. (Lima, et al, 2019) Fourthly, developing tools to help and guide the students and instructors throughout the activities (Farag, 2016). Finally, Assessment drives learning (Havard \&Olinzock, 2005).

The developed design has included the ODFs as an integral part of the program. It merged two important activities: mentorship and online discussion. Firstly, this Mentorship service changes the extra-curricular, optional, contact between students and faculty/mentors into an integral part of the curricular activities, where their active participation is monitored and assessed. Secondly, the listserv activity (online discussion forum) is planned and moderated by the fellows. The discussions are tailored around different themes suggested by the fellows themselves. Fellows are responsible for the success of the discussion which will improve their ownership, involvement, and quality of the contributions.

In the developed model, student and faculty guides are prepared by the management team to facilitate the fellows' and mentors' journey in this activity. The developed guide aimed to establish a track and vehicle for the fellows to reach the end of this activity safely. Both formative Summative assessments were used. The fellow's contributions in the discussion should be assessed by the coordinator, mentors, and fellows (self \& peer assessment). The activity accounts for $50 \%$ of the practical scores in the program.

Figure 2. Mentorship/Listserv activity model

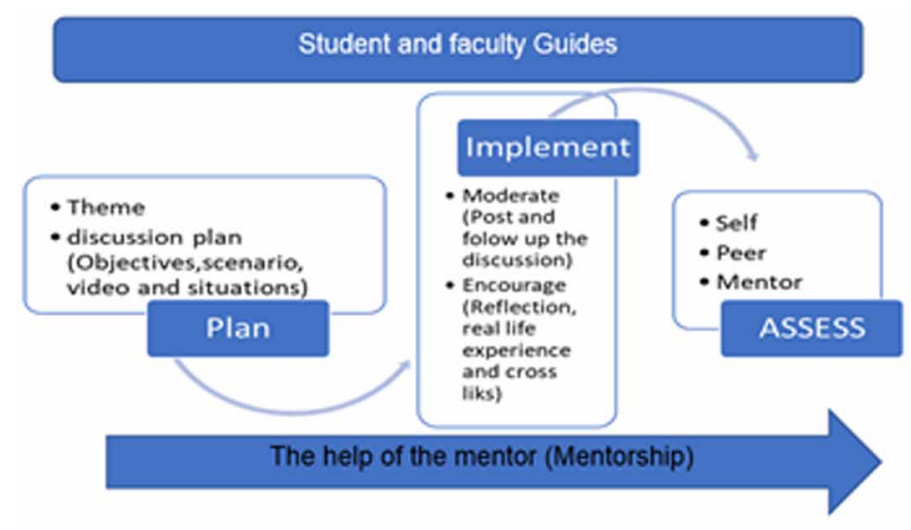




\section{c. Evaluate and reflect}

The new design was implemented for one round. Then a satisfaction questionnaire was used to evaluate the role of the student guide in the ODFs. A 31-items questionnaire was developed by the researchers to evaluate the student guide. The questionnaire has three main subscales: layout, content, and impact on performance. The questionnaires had a 5-point Likert-type scale from disagree entirely (1) to agree entirely (5). The Questionnaire was sent to ten Medical Education experts for face and content validity. It was modified according to their comments. The questionnaire was sent after the discussion as an email attachment to the fellows on their email. All the participants in the ODF, 62 fellows, were requested to complete and submit the questionnaire. The questionnaire was completed and submitted by 45 fellows. The questionnaire data were analyzed by SPSS 25 package as Frequencies and distribution. Further evaluation of the effect of this new design on the quality and quantity of the discussion will be conducted in further studies.

\section{RESULTS}

This section is presented in two subsections: evaluation of online discussion and success factors for implementing ODFs

a. Evaluation of the online discussion using the old ODFs design:

The evaluation revealed that $33 \%$ of the participants had no input in the online discussion. While $30 \%$ of the participants rarely posted and $2 \%$ of the participants posted consistently and productively. $38 \%$ of the participants posted between 2 to 5 posts per theme, each theme lasts for two weeks. Both the content and the interaction were insufficient. In which $30 \%$ of the participants provide regurgitation of information, $27 \%$ of the participants provide a clear explanation of the available information, $10 \%$ of the participants explain available information using relevant examples and only $1 \%$ of the participants articulate available information to expand on ideas presented, including the use of examples.

Additionally, $45 \%$ of the participants paraphrased the available information, only $1 \%$ of the participants critically discussed the available information. While $41 \%$ of the participants provide narrow and limited knowledge, $16 \%$ of the participants provide a wider view of the topics discussed. Finally, $26 \%$ of the participants showed no engagement with other learners' contributions and only $2 \%$ of the participants developed some solutions as a result of interaction and $17 \%$ of the participants engaged with the work and discussion of other learners.

b. Success factors for designing and implementing online discussion as shown in figure 4:

1. Merging of two activities (Mentorship and online discussion)

The focus group has identified the merging of mentorship as an important tactic for a successful discussion. The mentors identified several effects of mentorship on the online discussion: positive, undesirable, competencies of e-mentor and characteristics of the mentorship process.

\section{a. Positive effect of mentorship}

Five instructors view positive effects of a mentorship program on the online discussion they stated that mentorship can 'Help the students to select the theme and plan for the discussion', 'Improve the quality of the online discussion', 'Track the discussion', Add an expert opinion' and, 'Encourage the participation and increase the motivation'. 


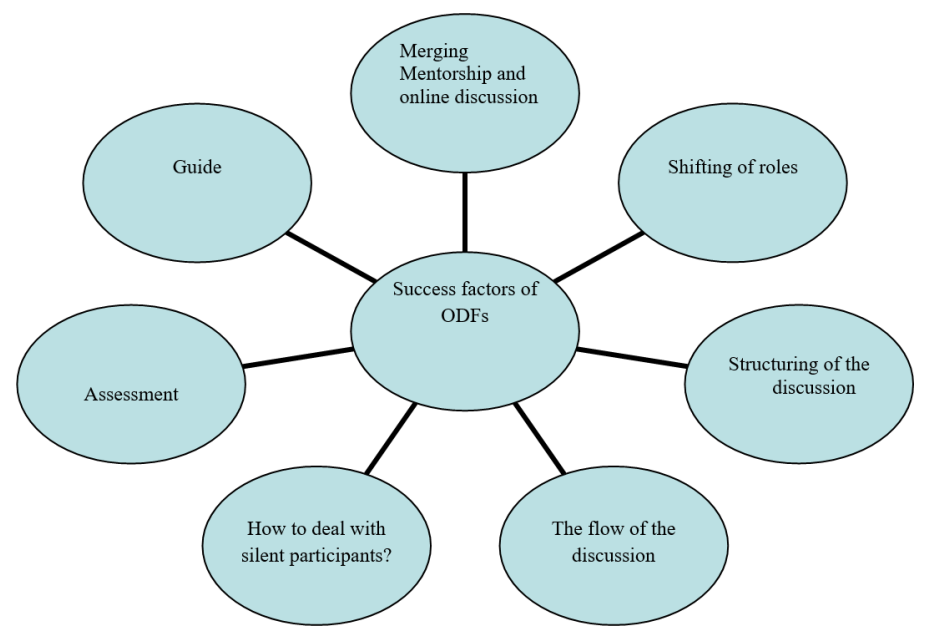

\section{b. Undesirable effect of mentorship}

However, four instructors identified negative effects of mentorship on online discussion 'It can limit the self-regulated learning as it may hinder autonomy', 'It conflicts with adult learning', 'May cause over guidance and control of the discussion', 'If the mentors are not volunteers, the discussion may be a burden and time consuming that may, in turn, affect the quality of the discussion'.

\section{c. Mentorship process}

Regarding the process of mentorship and the online discussion, they have agreed that group mentoring is better than an individual. They suggested that the mentor to mentee ratio can be starting from 1 to 5 up to 1 to 10 . They preferred the use of virtual contacts through the available applications as Zoom, Skype or What's app. However, two instructors stated that it may be better to allow the group to decide the preferable way of communication but at the same time announce a communication plan from the start of the activity and follow it. The communication plan was agreed upon by other instructors, but they added that the frequency of the meetings should be increased at the start and before the discussion. According to one of the instructors 'mentor needs to break the ice, know the group, and set ground rules at the start. Also, they need to meet frequently to prepare the discussion plan'

\section{d. Role and competencies of e-mentor}

Lastly the role of the e-mentor, the majority selected that the e-mentor is either a guide or facilitator. However, three instructors agreed that the role of the e-mentor may differ throughout the program either coach, motivator, or consultant. According to one of the instructors 'Yes... he/ she may have to be an information provider or modifier according to their situation, beginning of the activity or planning their discussion'. Instructors identified several competencies that e-mentor should have as good communicators, problem solvers, leaders, knowledge about adults, mentoring and eLearning theories. Then they identified the communication skills as the main competency that may differ in e-mentor and mentor. According to one of the instructors ', the challenges facing the virtual teams will need good communication skills and different skills that can cope with the virtual nature. Those challenges can be lack of face-to-face contact, lack of technical skills, building trust and the difference in time and schedule as stated by four instructors. 


\section{Shifting of roles}

The fellows are playing different roles in the discussion as participants or moderators. They shift roles in which each fellow should be a moderator for one time and an active participant in the other discussions. The moderator has a significant role in structuring the discussion (planning, process, and assessment). The other fellows rather than the moderators are requested to be active participants in all the discussions during the program learning. Participants should respond to the moderators' plan; clarify and justify their opinions and include examples from the real-life experience. They should apply knowledge and link theory to practice. It is important to respond to the moderators' posts as well as the other fellows' posts.

\section{Structuring of the discussion}

The structuring of the discussion included several factors under two main categories: planning $\&$ process.

\section{a. Planning}

The group should communicate to select the theme, formulate the objectives, and construct a creative, attractive, and genuine discussion plan. This plan is essential to run a productive discussion and engage other fellows.

In planning, instructors have suggested in the focus group that duration should vary according to the theme but with a minimum of 1 week and a maximum of 10 days to give chance for most of the students to engage and contribute to the discussion. According to one of the instructors, 'the duration should consider the early stage of silence'. They agreed that themes should not be dependent on each other, but they should be complementing the units. Additionally, it was suggested that 5 to 7 moderators in each group are appropriate while all the students should contribute to the discussion as this may allow sharing of experience and motivate others to share. The number of the discussions may vary according to the duration of the study however, three to five discussions may provide sufficient coverage of important themes. Regarding the role of the moderators and faculty, they stated the moderator should select the theme, develop the plan, coordinate the follow of the discussion, and encourage students to generate discussion. The faculty should provide the general guidance without direct interference in the discussion, but the main role is in the orientation, assessment, and feedback. According to one of the instructors 'faculty should play a mentor and assessor role; however, it is important to allow autonomy of the group and avoid domination of the process'.

\section{b. Process}

Once the discussion is started, Moderators should follow the plan. However, their posts should be sensitive and responsive to the flow of the discussion. The posts should encourage active and reflective responses from the participants. It should foster the generation of ideas and the flow of real-life experiences. Additionally, it is important to encourage the participants- moderators' communication as well as the participants-participants communications. Moderators should play devil to enrich the discussion.

According to the focus group responses, the second category is the process that has three subcategories. Firstly, about the content, Instructors agreed that the topic should be authentic, updated. Five instructors preferred to give the students or the moderators the autonomy to select the topic while the other five instructors suggested setting criteria or suggestion lists then allowing the moderators to select from it. According to one of the instructors 'themes should be directly related to their daily 
work. This may encourage the reflection and sharing of real-life experience'. According to one of the instructors ', if the same topic is covered in the educational unit, students may post their assignments or use others' ideas. However, it is preferable to be complementary to the educational units.

Regarding the presentation of the content, instructors agreed on one main concept to be used by all students in the discussion: videos, links, articles. According to one of the instructors 'we should consider the variety of learning styles and personality traits while deciding the presentation of the content'. The post of objectives and timetable before the start of the discussion will prepare the students for the activity and add an organizational outline to it. The use of scenario and reflection, both served as the main goal of the activity which is the share of ideas and experience. According to one of the instructors 'they can reach the literature from many different sources but the uniqueness of this activity hides in sharing all these minds and experiences on one table'.

Whereas the interaction, three instructors suggested that the end and start of the discussion can be flexible according to the responses. However, seven other instructors believed that it should be fixed and follow the timetable. According to one of the participants, "the flexibility in the start and end may be mistakenly used especially by the presence of shy participants.

\section{The flow of the discussion}

The most important point under the presentation category as agreed by seven instructors is the crosslinks. Crosslinks also serve two subcategories related to the presentation and interaction subcategories. Crosslink is an important factor that may allow bifurcation of the discussion from one-to-one technique to one to all. This factor should be mastered by the moderators in which they should play the devil and generate side discussion between students based on the analysis of their posts. According to one of the instructors 'differences in opinions can generate discussion more than similarities do'. The flow of the discussion, as shown in figure 4, is the moderators post the question/ scenario according to the timetable then students share their experience. The moderator should synthesize their contributions and identify similarities, differences and play devil to find a common interest between the students. This factor will generate crosslinks between the students. Moreover, it may encourage other students to contribute to the discussion.

\section{How to deal with silent participants?}

One significant problem as identified by instructors and literature is the silent participant. Instructors agreed that it is important to identify the cause of this silence then suggest a way of encouragement. According to one of the instructors 'the silence can mean several things and each situation may need a different solution'. They identified several causes for the silence and hypothesized solutions. These solutions were the same factors that were suggested for encouragement as shown in table 1. Additionally, four instructors suggested that the mentor should give extra attention to the silent participant, but two instructors disagreed. According to one of the instructors, 'We should do nothing; adult learning principles interfere with knocking on each door'.

\section{Assessment of the activity}

The assessment was identified as the main success factor for implementing ODFs by the focus group participants, six instructors agreed that it is extremely important for this activity to be graded. Moreover, three of the instructors added that it should account for a significant percentage of the total grade. As previously mentioned in the role of the mentor, all the instructors agreed on the role of feedback in shaping the discussion planning and implementation. Four instructors emphasized 
Figure 4. Shows the follow of discussion and crosslinks

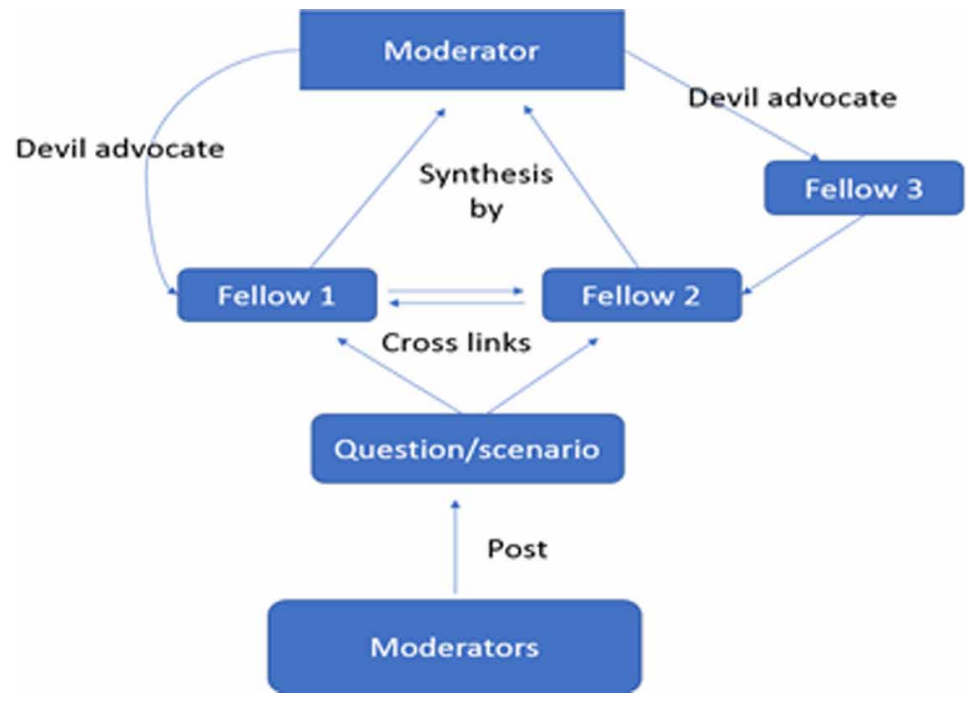

Table 1. Shows the causes of participant silence and suggested solutions

\begin{tabular}{|c|c|}
\hline Reasons of silence & Solutions \\
\hline Shyness & $\begin{array}{c}\text { Mentorship program } \\
\text { Acknowledge limited participation then encourage more elaboration }\end{array}$ \\
\hline Busy schedule & $\begin{array}{c}\text { Asynchronous activity and flexibility in the timetable } \\
\text { Bonus marks }\end{array}$ \\
\hline $\begin{array}{c}\text { Lack of knowledge about the } \\
\text { importance of this activity }\end{array}$ & $\begin{array}{c}\text { Mentorship program } \\
\text { Include old students that are interested in Medical Education to discuss with the student } \\
\text { and keep the discussion motivating } \\
\text { Orientation }\end{array}$ \\
\hline $\begin{array}{c}\text { Lack of knowledge about } \\
\text { the topic }\end{array}$ & $\begin{array}{c}\text { Pre-discussion materials } \\
\text { Carelessness }\end{array}$ \\
& An appropriate portion in the summative assessment \\
\hline Fear of judgments & Set ground rules \\
\hline
\end{tabular}

that the feedback should be timely, constructive, and motivating. Lastly, four instructors suggested that the mentorship activity should be evaluated by the mentor and the students.

\section{Guides}

All the instructors involved in the focus group have suggested the use of student and faculty guides as an essential success factor that can cope with all the categories from planning to assessment. Four instructors suggested that the layout should be user friendly and simple. It also should be Comprehensive, clarifying different roles and requirements using simple vocabulary. Moreover, content should be organized, answering all inquiries and informative. One instructor added that it 
should contain Guidelines, steps, importance, educational benefits, what to do and what not to do, how to deal with different discussants and evaluation forms'. Three of the instructors suggested that the evaluation forms should be simple, short and on a scale. Six instructors suggested that evaluation should be regular, and students should submit the evaluation forms before their graduation. Regarding the change the guide may add to the discussion, one instructor added 'it may put ground rules, make everything clear for students, make it easier for the team to explain everything to every student'. Another instructor added 'Sure, it should provide a systematic approach to the discussion and ensure being on the right track'.

The satisfaction questionnaire results revealed that $86 \%$ agreed that it is important to read the guide at the start of the study as it helped them to take the discussion more seriously $89 \%$. While $84.7 \%$ of the participants agreed that the guide improved their performance in the discussion. Firstly, it helps them to understand ML activity and their role as moderator and participant as agreed by $94 \%$. Moreover, it improved both the quality and quantity of the contributions for $89.1 \%$ of the participants. Regarding the quantity, it encourages $73 \%$ to reply to other fellows' posts but it encourages $47 \%$ to actively participate in all the discussions. While as it increased the depth of the contributions by $78 \%$. It also helped $82 \%$ to focus on real-life experiences and reflection.

\section{DISCUSSIONS}

An initial objective of the project was to identify the key success factors for implementing online discussion. Additionally, the current study explores the advantages of merging two activities, e-mentoring and online discussion, to improve the quality and gains of the online discussion.

The current study documented the cruciality of the supervision and guidance for online discussion to achieve its goal. Two types of supervision were highlighted by the current study: Mentorship and Moderation. First, the moderator role was found as the most important success factor. It seems possible that it was selected because the moderators play a significant role in the discussion forum through the different phases of the discussion: the planning, implementation, and elevation. Additionally, they are involved in the selection of the theme, preparation of the plan that are triggers for the discussion as moderator posts may stimulate or hinder the discussion. In a similar vein, Jo et al. (2017) and Williams et al. (2015) highlight research that demonstrates that discussion forums tend to remain at a superficial level unless the discussion was actively facilitated.

Additionally, the current study has suggested another unique factor which is assigning moderators from the students and shifting their roles as moderators and participants during the whole activity. This factor helps students to engage in active presence in the discussion. This presence involved both the cognitive and social aspects that may help the students to take the discussion more seriously. Moreover, this factor fosters the students to exert serious effort for the success of each discussion forum because they are responsible for the activity as the discussion is student-centred now. This effort will direct the learners' cognitive engagement and ensure students' high-level cognitive effort which is crucial for a successful learning experience in online discussions as it is closely related to the learning achieved in knowledge and skill acquisition (Oh and Kim, 2016). Additionally, this factor provides the students with a sense of ownership to the activity that will motivate participation with high-quality contributions reflecting critical thinking and deep understanding.

Similarly, the e-mentor role that has been found by the current study to have several positive effects on the discussion as guidance, encouragement, and motivation that will improve the quality of the discussion and the achievement of the students. Park (2015) has stated that the mentor's involvement in the online discussion forums stimulates the students' analytical thinking. As when instructors enhance their engagement in a discussion, they help build instructor presence, which in turn enhances students' learning experience through fostering learner-instructor interaction (Cho \& Tobias, 2016; Davis, 2018). However, it is important to avoid over guidance and to bear in mind the principles of adult learning. Over Guidance or domination may hinder the motivation and self-learning skills that 
may lead to poor performance (Bromme, et al, 2005). Taken all together, adding mentorship to the discussion activity will help in the improvement of the quality and quantity of the discussion and this point was agreed by previous studies that highlighted the different effects of e-mentor (Sabel et al. 2014; Choi et al. 2019; Ramani, et al 2020)

The current study also advocated the importance of structuring the discussion, the discussion's themes, presentation and finally the assessment and feedback. Structuring the discussion may help students to prepare themselves and take the activity more seriously. It helps to achieve a higher cognitive dimension of knowledge building, constructing meaning, and linking theory to practice (Delaney, et al, 2019). The selection of an attractive and updated theme will foster the student-content interaction and motivation that in turn will improve the performance. Moreover, the quality of the contributions was also highlighted in the current study findings with a massive emphasis on the importance of reflection and sharing of personal experience. Through reflection, learners make informed decisions based on their past practices and responses to issues (Clarke, 2004). Also, the current study recommends avoiding direct copy from the literature and urges the use of each students' own words. Because the current study echoes the constructivism principles that showed that learning occurs through building upon previous knowledge and constructing meaning by chunking new and old information. (Kim, 2013). This deep approach of learning needs critical thinking and a deep understanding of the questions and answers that may be hindered by copying from the literature. The quality of the posts was previously discussed by other studies that recommended students to make arguments, diagnose misconceptions, negotiate perspectives, share personal experiences, challenge accepted beliefs, and demand reason for conclusions, and all of these are important cognitive presence in deep learning.

The arrangement of the students into groups was another factor suggested in the findings. The use of groups is favoured in online discussions. It may help both the students and mentor; help the student to be active participants in all the steps of the discussion and not rely on each other. The results revealed that dividing students into groups. It may also provide the mentor with a chance to closely mentor the discussion and strengthen the relationship between the mentor and students. Several previous studies have favoured the division of the students into small groups (7-14 students) as it affected the students' participation in the online discussion. (Kim, 2013; Alzahrani, 2017).

A key challenge and frustration to the discussion interaction, emphasized by mentors, were concerns about the participants who did not respond despite numerous attempts to reach out to them (silent participants) and how to motivate them to contribute to the discussion. Findings showed the need to have more platforms for delivering feedback and acknowledged the need to continually work on mentoring relationships to counteract complacency. The current study also had proposed some factors to deal with this participant that added to earlier studies which prepared guides for dealing with silent participants (Creelman, 2017, Wilton, 2018).

However, the current study revealed that not all silent participants are not learning. The cause for this silence may be shyness, fear of judgment, unfamiliarity with the discussion technology and personality trait. Others are lurkers, who only read other student posts without making any contribution to the online discussion, as described by several researchers (Zhu, 2006; Palmer \& Holt, 2010). In a similar vein, Ebner and Holzinger (2005), observed that visible interactions do not necessarily indicate learning. On the other hand, Nagel, et al (2009), who found a relationship between visible contributions and course grades in their small study involving 22 students, concluded that read-only participation should be avoided. Thus, it seems that how students interact or learn in online discussion warrants further research.

The assessment was another important factor identified in the current study. Both summative and formative assessments are identified. Feedback may guide the students, provoke inquiries and foster the instructor-learner activity and create a dialogue and channel with the students. This dialogue may also increase the student cognitive engagement (Jo, et al, 2017). However, students are not likely to engage in an online activity that does not officially contribute to the final course mark (Chu, et al 2012). Studies, however, hinted that online discussion is often evaluated with numbers of posts and 
accounts for $10 \%$ of the total grades Cho and Cho (2017). This small portion of the evaluation of the online discussion accounts of the final grades may cause the students not to take online interaction with other students seriously.

Finally, the use of guides for either students or faculty may contribute to solving one of the greatest challenges of online discussions which is the low student participation and engagement (Caspi et al., 2006). The reasons for this challenge were previously identified in several studies, the students' confusion about their role, instructor expectations, clear deadline, and description of the online discussion nature (Pena-Shaff \& Altman, 2015). As the guide may provide all the needed information that will assist the fellows to overcome these challenges. In turn, it will help in the improvement of the quality and quantity of their contribution. Additionally, it will improve the student's engagement and the effectiveness of the online discussion (Aloni \& Harringto, 2018). In online activities, learners need more guidance and structure than face-to-face ones. Structuring helps them follow, monitor, and reflect on the activity. This clarity helps the student to understand their role and guide them throughout the task.

\section{LIMITATIONS}

Although the current study does not lack methodological rigour, the findings must be interpreted with caution. The findings might have related to the experiences of the number of experts presented and therefore cannot be transferred to a larger population. Likewise, it is important to note the sample size in the current study while interpreting the study findings.

\section{CONCLUSION}

The results of our analysis are relevant to the distance learning community and can help instructors, developers, and students to help improve the quality and use of forums. The identification of the success factors identified a great potential of empowerment of students and structuring the discussion. Adding further guidance and support by mentorship and student guides will help in overcoming many challenges to ODFs. A recommendation for further study of the effect of the developed design on both the quality and quantity of the discussion and exploration of the fellow's opinion in these themes.

\section{Funding}

The authors did not receive any funds.

\section{ACKNOWLEDGMENT}

The authors acknowledge the co-directors of the Joint Master of Health Professions Education between Maastricht and Suez Canal Universities for their help and cooperation. Data Availability Statement: The data that support the findings of this study are available on request from the corresponding author. 


\section{REFERENCES}

Abawajy, J., \& Kim, T. (2011). Online learning environment: taxonomy of asynchronous online discussion forums. International Conference on Advanced Software Engineering and Its Applications, 706-14. 10.1007/9783-642-27207-3_76

Afify, M. K. (2019). The influence of group size in the asynchronous online discussions on the development of critical thinking skills, and on improving student's performance in online discussion forums. Int $\mathbf{J}$ Emerg Technol Learn., 14(5), 132-152. 10.3991/ijet.v14i05.9351

Aloni, M., \& Harringto, C. (2018). Research-Based Practices for Improving the Effectiveness of Asynchronous Online Discussion Boards. Scholarship of Teaching and Learning in Psychology. American Psychological Association, 4(4), 271-289. 10.1037/st10000121

Alzahrani, M. G. (2017). The effect of using online discussion forums on students' learning. TOJET: The Turkish Online Journal of Educational Technology, 16(1), 164-176. doi:10.5430/wje.v7n2p

Anderson, T. (2004). Towards a theory of online learning. Theory Practice Online Learn, 2, 109-119.

Bakharia, A., \& Dawson, S. (2011). SNAPP: a bird's-eye view of temporal participant interaction. Proceedings of the 1st international conference on learning analytics and knowledge, 168-73. 10.1145/2090116.2090144

Balaji, M. S., \& Charkrabarti, D. (2010). Student Interactions in Online Discussion Forum: Empirical Research from 'Media Richness Theory' Perspective. Journal of Interactive Online Learning, 9(1), 1-22. doi:10.5281/ zenodo.1097074

Benbunan-Fich, R., \& Hiltz, S. R. (1999). Impacts of asynchronous learning networks on individual and group problem solving: A field experiment. Group Decision and Negotiation, 8(5), 409-426. doi:10.1023/A:1008669710763

Brinton, C., Chiang, M., Jain, S., Lam, H., Liu, Z., \& Wong, F. (2014). Learning about social learning in MOOCs: From statistical analysis to generative model. IEEE Transactions on Learning Technologies, 7(4), 346-359. doi:10.1109/TLT.2014.2337900

Bromme, R., Hesse, F. W., \& Spada, H. (2005). Barriers, biases and opportunities of communication and cooperation with computers: introduction and overview. In Barriers and biases in computer-mediated knowledge communication and how they may be overcome (pp. 1-14). Springer.

Brower, H. (2003). On emulating classroom discussion in a distance delivered OBHR course: Creating an online learning community. Academy of Management Learning \& Education, 2(1), 22-36. doi:10.5465/ amle.2003.9324013

Caspi, A., Chajut, E., Saporta, K., \& Beyth-Marom, R. (2006). The inñuence of personality on social participation in learning environments. Learning and Individual Differences, 16, 129-144. doi:10.1016/j.lindif.2005.07.003

Chang, Liang, Shu, \& Chiu. (2015). Alteration of Influencing Factors of e-Learning Continued Intention for Different Degrees of Online Participation. International Review of Research in Open and Distributed Learning, 16(4), 33-61.

Cho, M.-H., \& Cho, Y.-J. (2017). Self-regulation in three types of online interaction: A scale development. Distance Education, 38(1), 70-83. doi:10.1080/01587919.2017.1299563

Cho, M.-H., \& Tobias, S. (2016). Should Instructors Require Discussion in Online Courses? Effects of Online Discussion on Community of Inquiry, Learner Time, community of Inquiry, Learner Time, Satisfaction and Achievement. International Review of Research in Open and Distributed Learning, 7(2). Advance online publication. doi:10.19173/irrodl.v17i2.2342

Choi, A. M. K., Moon, J. E., Steinecke, A., \& Prescott, J. E. (2019). Developing a culture of mentorship to strengthen academic medical centers. [DOI: doi:10.1097/ACM.0000000000002498]. Academic Medicine, 94(5), 630-633.

Chu, S. K. W., Chan, C. K. K., \& Tiwari, A. F. Y. (2012). Using blogs to support learning during internship. Computers \& Education, 58, 989-1000. scholar.google.com/citations?user=7IQasCgAAAAJ\&hl=en 
Clarke, M. (2004). Reflection: Journals and reflective questions: A strategy for professional learning. Australian Journal of Teacher Education, 29(2), 1-13. doi:10.14221/ajte.2004v29n2.2

Coetzee, D., Fox, A., \& Hearst, M. A. (2014). Should your MOOC forum use a reputation system? Proceedings of the 17th ACM conference on Computer supported cooperative work \& social computing, 1176-87. $10.1145 / 2531602.2531657$

Creelman, A. (2017). NVL: Silent learners-a guide. Retrieved from http://lnu.divaportal.org/smash/get/ diva2:1171709/FULLTEXT01.pdf

Davis, G. (2018). Discussion forums [PowerPoint slides]. The Learning House, Inc.

Delaney, D., Kummer, T., \& Singh, K. (2019). Evaluating the impact of online discussion boards on student engagement with group work. British Journal of Educational Technology, 50(2), 902-920. doi:10.1111/bjet.12614

Dennen, V. P. (2005). From message posting to learning dialogues: Factors affecting learner participation in asynchronous discussion. Distance Education, 26(1), 127-148. doi:10.1080/01587910500081376

Ebner, M., \& Holzinger, A. (2005). Lurking: An underestimated human-computer phenomenon. IEEE. 10.1109/ MMUL.2005.74

Farag, M. (2016). An Instructor Guidelines and Group Size as Moderating Factors Affecting Quality and Quantity of Online Discussion Participation, Satisfaction and Learning. Journal of Arabic Studies in Education \& Psychology, 72, 417-552. doi:10.12816/0036696

Filippo, D., Fuks, H., \& de Lucena, C. J. P. (2009). Discussion forum coordination support in distance courses. Scie Interdiscip Stud Comput Sci, 20(1), 25-40. 10.4013/sct.2009.20.1.03

Funaro, G., \& Montell, F. (1999). Pedagogical roles and implementation guidelines for online communication tools. ALN Mag., 3(2), 1-9.

Garrison, D. R., \& Cleveland-Innes, M. (2005). Facilitating Cognitive Presence in Online Learning: Interaction Is Not Enough. American Journal of Distance Education, 19(3), 133-148. doi:10.1207/s15389286ajde1903_2

Gerosa, M., Filippo, D., Pimentel, M., Fuks, H., \& Lucena, C. (2010). Is the unfolding of the group discussion off-pattern? Improving coordination support in educational forums using mobile devices. Comput Educ, 54(2), 528-544. doi:10.1016/j.compedu.2009.09.004

Gilbert, P. K., \& Dabbagh, N. (2005). How to structure online discussions for meaningful discourse: A case study. British Journal of Educational Technology, 36(1), 5-18. doi:10.1111/j.1467-8535.2005.00434.x

Havard, B., Du, J., \& Olinzock, A. (2005). Deep learning: The knowledge, methods, and cognitive process in instructor-led online discussion. The Quarterly Review of Distance Education, 6, 125-135.

Hew, K. F., Cheung, W. S., \& Ng, C. S. L. (2010). Student contribution in asynchronous online discussion: A review of the research and empirical exploration. Instructional Science, 38(6), 571-606. doi:10.1111/j.13652729.2011.00454.x

Hollands, F., \& Tirthali, D. (2014). MOOCs: expectations and reality, Full report. NY Cent. Benefit Cost Stud. Educ. Teach. Coll. Columbia Univ.

Höver, K., \& Mühlhäuser, M. (2014). Evaluating a linked open online course. 2014 IEEE International Symposium on Multimedia, 375-80. 10.1109/ISM.2014.68

Jiang, Z., Zhang, Y., Liu, C., \& Li, X. (2015). Influence analysis by heterogeneous network in MOOC forums: what can we discover? Int Educ Data Min Soc., 242-249. https://files.eric.ed.gov/fulltext/ED560574.pdf

Jo, I., Park, Y., \& Lee, H. (2017). Three interaction patterns on asynchronous online discussion behaviours: A methodological comparison. Journal of Computer Assisted Learning, 33, 106-122. doi:10.1111/jcal.12168

Katz, S., Connelly, J., \& Wilson, C. (2005). When should dialogues in a Scaffolded learning system take place? EdMedia+ Innovate Learning, 2850-5.

Kim, J. (2013). Influence of group size on students' participation in online discussion forums. Computers \& Education, 62, 123-129. doi:10.1016/j.compedu.2012.10.025 
Knowlton, D. S. (2005). A taxonomy of learning through asynchronous discussion. Journal of Interactive Learning Research, 16(2), 155-177. doi:10.1007/s11251-006-0004-0

Koutropoulos, A., Gallagher, M. S., Abajiam, S., Ward, I., Hogue, R., Keskin, N., \& Rodriguesz, C. (2012). Emotive vocabulary in MOOCs: Context \& Participant Retention. Eur J Open, Distance E-Learning, 1-23. https://files.eric.ed.gov/fulltext/EJ979609.pdf

Lima, D., Gerosa, M. A., Conte, T. U., \& Francisco de M. Netto, J. (2019). What to expect, and how to improve online discussion forums: The instructors' perspective. Journal of Internet Services and Applications, 10(22). Advance online publication. 10.1186/s13174-019-0120-0

Liu, M., Kang, J., McKelroy, E., Harron, J., \& Liu, S. (2016). Investigating students' interactions with discussion forums, Facebook, and twitter in a MOOC and their perceptions. In: Revolutionizing Modern Education through Meaningful. E-Learning Implementation, 18-41. 10.4018/978-1-5225-0466-5.ch002

MacHado, C., MacIel, A., Rodrigues, R., \& Menezes, R. (2019). An approach for thematic relevance analysis applied to textual contributions in discussion forums. International Journal of Distance Education Technologies, 17(3), 37-51. doi:10.4018/IJDET.2019070103

Mazzolini, M., \& Maddison, S. (2007). When to jump in: The role of the instructor in online discussion forums. Comput Educ., 49(2), 193-213. doi:10.1016/j.compedu.2005.06.011

Nagel, L., Blignaut, A. S., \& Cronjé, J. C. (2009). Read-only participants: A case for student communication in online classes. Interactive Learning Environments, 17(1), 37-51. doi:10.1080/10494820701501028

Nakahara, J., Hisamatsu, S., Yaegashi, K., \& Yamauchi, Y. (2005). iTree: does the mobile phone encourage learners to be more involved in collaborative learning? Proceedings of the 2005 conference on Computer support for collaborative learning: learning: the next 10 years! 2005, 470-8.

Nandi, D., Hamilton, M., \& Harland, J. (2012). Evaluating the quality of interaction in asynchronous discussion forums in fully online courses. Distance Education, 33(1), 5-30. doi:10.1080/01587919.2012.667957

Oh, E. G., \& Kim, H. S. (2016). Understanding Cognitive Engagement in Online Discussion: Use of a Scaffolded, Audio-based Argumentation Activity. International. Review of Research in Open and Distributed Learning, 17(5). Advance online publication. doi:10.19173/irrodl.v17i5.2456

Palmer, S., \& Holt, D. (2010). Online discussion in engineering education: Student responses and learning outcomes. In L. Shedletsky \& J. E. Aitken (Eds.), Cases on online discussion and interaction: Experiences and outcomes', PP (pp. 105-122). IGI Global., doi:10.4018/978-1-61520-863-0.ch005.

Park, J. Y. (2015). Student interactivity and teacher participation: An application of legitimate peripheral participation in higher education online learning environments. Technology, Pedagogy and Education, 24(3), 389-406. doi:10.1080/1475939X.2014.935743

Pena-Shaff, J., \& Altman, W. (2015). Student interaction and knowledge construction in case-based learning in Educational Psychology using online discussions: The role of structure. Journal of Interactive Learning Research, 26, 307-329. scholar.google.com

Pendry, L., \& Salvatore, J. (2015). Individual and social benefits of online discussion forums. Computers in Human Behavior, 50, 211-220. doi:10.1016/j.chb.2015.03.067

Poquet, O., Dawson, S., \& Dowell, N. (2017). How effective is your facilitation? group-level analytics of MOOC forums. Proceedings of the Seventh International Learning Analytics \& Knowledge Conference, $208-17$. $10.1145 / 3027385.3027404$

Ramani, S., Thampy, H., McKimm, J., Rogers, G. D., Hays, R., Kusurkar, R. A., Schumacher, D. J., Kachur, E. K., Fornari, A., Chisolm, M. S., Filipe, H. P., Turner, T. L., \& Wilson, K. W. (2020). Twelve tips for organising speed mentoring events for healthcare professionals at small or large-scale venues. Medical Teacher, 25, 1-8. doi:10.1080/0142159X.2020.1737323

Rohfeld, R., \& Hiemstra, R. (1995). Moderating discussions in the electronic classroom. Academic Press.

Rowland, K. N. (2012). An Innovative Twist to Traditional Mentoring. Journal of Technology Management \& Innovation, 7(1). doi:10.4067/S0718-27242012000100015 
Sabel, E., \& Archer, J. (2014). Medical education is the ugly duckling of the medical world and other challenges to medical educators' identity construction: A qualitative study. Academic Medicine, 89(11), 1474-1480. doi:10.1097/ACM.0000000000000420

Sayfouri, N. (2016). Evaluation of the learning management system using students' perceptions. Med J Islam Repub Iran, 30, 460. https://www.ncbi.nlm.nih.gov/pmc/articles/PMC5419244

Stephens-Martinez, K., Hearst, M. A., \& Fox, A. (2014). Monitoring moocs: which information sources do instructors value? Proceedings of the first ACM conference on Learning@ scale conference, 79-88. $10.1145 / 2556325.2566246$

Ulrich, C., \& Nedelcu, A. (2015). Moocs in our university hopes and worries. Procedia: Social and Behavioral Sciences, 180, 1541-1547. doi:10.1016/j.sbspro.2015.02.304

Watson, A. (2008). Developing teaching practice for more effective use of synchronous discussion: a preliminary investigation. Proceedings Ascilite.

Williams, S. S., Jaramillo, A., \& Pesko, J. C. (2015). Improving depth of thinking in online discussion boards. The Quarterly Review of Distance Education, 16(3), 45-66.

Wilton, L. (2018). Quiet participation: Investigating non-posting activities in online learning. Online Learning, 22(4), 65-88. https://www.wbtsystems.com/learning-hub/blogs/increase-student-participation-online-discussions

Wise, A. F., Cui, Y., \& Vytasek, J. (2016). Bringing order to chaos in MOOC discussion forums with contentrelated thread identification. Proceedings of the Sixth International Conference on Learning Analytics \& Knowledge, 188-97. 10.1145/2883851.2883916

Xie, K., DeBacker, T. K., \& Ferguson, C. (2006). Extending the traditional classroom through online discussion: The role of student motivation. Journal of Educational Computing Research, 34(1), 67-89. doi:10.2190/7BAKEGAH-3MH1-K7C6

Xu, B., \& Yang, D. (2015). Study partners recommendation for xMOOCs learners. Computational Intelligence and Neuroscience, 15, 1-10. Advance online publication. doi:10.1155/2015/832093 PubMed

Zhao, H. (2016). Factors Influencing Self-Regulation in E-learning 2.0: Confirmatory Factor Model. Canadian Journal of Learning and Technology, 42(2).

Zhao, N., \& McDougall, D. (2005). Cultural factors affecting Chinese students' participation in asynchronous online learning. In G. Richards (Ed.), Proceedings of World Conference on E-learning in Corporate, Government, Healthcare, and Higher Education (pp. 2723-2729). Chesapeake, VA: AACE.

Zhu, E. (2006). Interaction and cognitive engagement: An analysis of four asynchronous online discussions. Instructional Science, 34(6), 451-480. 
Enjy Abouzeid M.: MSc, Medical Doctorate, University of Leeds \& FOMSCU. She is a Lecturer in the Medical Education Department. She is working as Head of the exam committee (MCQs) for the undergraduate phase. Also, she is a Vice President of the assessment and evaluation unit in the Faculty of Medicine, Suez Canal University, FOMSCU. She is a Faculty in the Diploma of Health Professions Education program (DHPE) and an Online discussion coordinator of the Joint Master of Health Professions Education between Maastricht and Suez Canal Universities (JMHPE) and DHPE. ORCID ID:https://orcid/.org/0000-0002-9431-6019

Anshoo Agarwal : Professor and Coordinaor; Department of Pathology,Faculty of Medicine ;Northern Border University; Arar, Kingdom of Saudi Arabia, M.B.B.S. King George's Medical College Lucknow,MD in pathology and Master of Health Professions Education (JMHPE); Maastricht University (UM) jointly with Suez Canal University (SCU), Egypt. Past positions : Associate professor \& and Incharge, Department of Pathology. Faculty of Medicine, Faculty of Dentistry, University Technology MARA, Shah Alam, Selangor, Malaysia, Professor \& Chairperson (Pathology \& Forensic Medicine), RAK medical college and Health sciences University, United Arab Emirates. ORCID ID :https://orcid.org/0000-0002-8675-3083

Janneke M. Frambach is assistant professor at the Department of Educational Development and Research, School of Health Professions Education, Faculty of Health, Medicine and Life Sciences, Maastricht University, Maastricht, the Netherlands. Her research program focuses on globalization and internationalization in health professions education. ORCID: https://orcid.org/0000-0003-1527-6539. 